\section{ARSENIC IN FLY-PAPERS.}

By WILLIAM M. ORD, M.D.Lond., F.R.C.P., Physician to St. Thomas's Hospital.

THE following case is recorded with the object of drawing attention to a source of poisoning not commonly known, namely, the presence of a soluble form of arsenic in many of the sheets sold under the name of "fly-papers".

A boy of eight years was admitted to Charity Ward, St. Thomas's Hospital, at 7.15 P.x. on the 18th May last, unconscious, and to all appearance suffering from belladonna-poisoning. It was asserted that the symptoms had come on at about 5 P.M.; and, as the friends had already suspected poisoning, three explanations were offered by them for the information of the hospital officials.

1. At $10.30 \mathrm{~A}$. M., the child had been challenged by his sister to drink the water from a plate in which a fly-paper was soaking. He was said to have drunk some : an example which was not followed by his sister.

2. The sister was attending at the Royal South London Ophthalmic Hospital, and had been there supplied with a green lotion for application to the eyes. This lotion, according to the mother's statement, was kept in a cupboard, and inaccessible to the child. It had been placed in the cupboard at $4 \cdot 30$, on her return from the hospital. The child had been strictly forbidden to touch this lotion.

3. The friends of the patient were inclined to think that some sweet. meats of which the child had partaken in the afiernoon were the vehicles of the poison.

The history and symptoms were collected by Mr. Walter Tyrrell and Mr. W. H. Battle, house-physicians in the hospital.

It appeared that towards 5 P.M., shortly after he had eaten some of the sweets mentioned, his mouth became dry. This led him to drink a quantity of water, which made him no better. Presently he began to feel giddy and to fall about, not knowing where he was. He dared not sit, on account of a fte'irg that he should tumble off from the chair; and he felt secure only in the kneeling posture. IIe had no pain, no romiting, no diarrhoe. He became incoherent in his talk
for the first time at 5 P.M, and soon after that symptoms of retention of urine attracted attention. As he was rapidly becoming helpless, he was led or cnrried to a medical man, and passed on by his assistant to the hospiral.

By this time, 7 P.M., he was quite unconscious of what was passing around, not showing the least recognition of his mother; and he could not walk or stand. The pupils were extremely dilated, and insensible to light. The ophthalmoscupe was used without the slightest sign of annoyance to the patient. No abnormity was detected within the eyes. The conjunctiva retained their sensitiveness, and when they were touched the patient turned over, put up his hands, and moved his head. The skin of one of the legs being pricked, the patient showed decided symptoms of displeasure, moved the leg away, and for the first time made a little noise. Ile could not be induced to protrude his tongue, but it could be seen and felt to be perfectly dry. He could not be made to answer questions, and indeed did not utter a word. The pulse was 72, regular and full; the breathing regular, and not stertorous. The bladder was much distended, a little urine dribbling from the penis. His condition was from these symptoms inferred to be due to belladonna-poisoning.

The urine having been drawn off (and, unfortunately, thrown away), a hot bath was administered. This was followed by noisy delirium. He was now ordered to have five drops of tincture of opium every two hours as long as he was noisy; but, after the first dose, the treatment was changed, and a sixth of a grain of extract of physostigma was given every two hours during the continuance of the noisy delirium. The bladder was emptied again not long after, and the urine was found not to cause dilatation of the pupil of the eye of A. B., into which a feN drops were introduced. The water from the fly.paper also had no effect; but the lotion referred to speedily caused dilatation in the eye of C. D.

The noisy and very troublesome delirium lasted till $5 \mathrm{~A} . \mathrm{M}$, but the patient did not return to anything like natural consciousness till I I A.M. He then voluntarily stated that he had drunk the liquid from the flypaper plate; and, in answer to questions, denied altogether acquaint. ance with the eye.lotion. Control of the bladder was now re-established, and the physostigma was discontinued. On the 2oth (third day), although he could stand, he staggered in walking; and it was not before the $23^{\text {rd }}$ that he became quite steady on his legs. After that, his recovery was uninterrupted; and he was discharged on the 25th.

REMARKs. - There can be no reasonable doubt as to the poison which gave rise to the symptoms above recounted. It was certainly some preparation containing atropia. The sweets were not in fault, for they were taken freely by the sister of the patient and by others at the time and subsequently without bad results. The lotion undoubtedly contained belladonna, apparently in the form of the green extract rubbed down with water. And, as no other substance comprehending belladonna in its composition was discovered, the lotion, in spite of the contrary assertions of the children and the mother, was almost certainly the poisonous agent. The fly-papers incriminated were, as well as the lotion, examined chemically by Mr. Plowman, our able and conscientious apothecary. And I cannot do better than quote passages from a letter addressed by Mr. Plowman to the Phar. maceutical fournal of June 22nd, 1878 , in which his conclusions are iully stated.

" My particular ohject in writing this letter is to call attention to the fact that fly-papers commonly contain arsenic. This may be well. known to the majority of your readers, but it was certainly unknown to myself and to several to whom I have spoken on the subject. In fact, one stated that he had last week informed a lady customer that fiy-papers were only fatal to insect life. In order to ascertain whether fly-papers generally contain arsenic, and, if so, to what extent, I procured six samples, bearing the names of six different makers. In five
of the six I found arsenic; and, on estimating the amount, obtained the following results, being in each case the mean of two experiments : No. 1, 1.92 grains; No. 2, 2 grains; No. 3, 2.95 grains; No. 4, 6.25 grains; No. 5, 5.36 grains. The sixth kind examined was papier moure. This contained no arsenicum in any form whatever. It was very bitter to the taste ; and, as it contained no strychnia, I inferred that it contained some preparation of quassia. I endeavoured to isolate quassiin from a number of the papers, but towards the end of process lost the whole, and I have not had time to repeat the operation. In all the arsenical fly-papers, the arsenic existed chiefly as free arsenic $\left(\mathrm{As}_{2} \mathrm{O}_{3}\right)$, for the aqueous solutions were faintly but distinctly acid; and, though nitrate of silver gave reactions for arsenites, ammonionitrate of silver gave very much more decided reactions. . .

"I have no wish to cause additional restrictions to be imposed on the chemist in the carrying on of his business; but, supposing that a chemist sold some of No. 4 paper without registering the sale, etc., and further, supposing that a child swallowed the liquid with fatal results, and that an inquest was held, there is much probability that the coroner would severely censure the seller, although he (the seller) might be perfectly ignorant of the poisonous nature of the fly-paper. Independently of this consideration, I think that there are few men who would wittingly take the responsibility of selling a number of sheets, some of them containing over six grains of arsenic, to be moistened with water and distributed in open plates and dishes through. out dwelling.houses.

"I consider, therefore, that it behoves all chemists in business to ascertain the nature of the fly-papers which they sell, and to cease retailing those which may be found on examination to contain a poison which might be fatal to human life."

When it is seen that as much as five grains of a soluble preparation of arsenic have been found in a single paper, and that this paper when used is by direction placed in a plate containing water, the existence of a serious public danger is evident. And, again, when the presencethe often dangerous presence-of arsenic in wall-papers, dress-colourings, and other fabrics is considered, the necessity for legislation in re. stajction of the use of this deadly substance appears to be pressing.

\section{ON ULCERATION OF THE FRANUM LINGUE IN PERTUSSIS.}

By ROBERT CORY, M.B.Cantab., Assistant Obstetric Physician to St. Thomas's Hospital.

Dr. Firiot having lately added his experience to that of Dr Maccall and of Dr. Morton with regard to the presence of ulceration on the frenum of the tongue in cases of whooping-cough, it may, perhaps, be of some service if I give my experience obtained from the children attending as out.patients at St. Thomas's Hospital.

The number of cases of whooping-cough during the last two years, in which the franum of the tongue was examined, amounted to 84. Of these 84 cases, 27 of them had ulceration of the frænum, giving a percentage of 32.14. This, it will be observed, is greater than that of Dr. Elliott ( 25 per cent.), but considerably less than that of Dr. Maccall (44 per cent.), and of Dr. Morton (4I per cent.) I, however, agree with Br. Morton in thinking that, if the cases coald all have been followed up, the ulcer would have been found to exist even in a greater proportion than 41 per cent.; and I therefore look upon Dr. 